\title{
Erratum to: Optimization of Noise in Non-integrated Instrumentation Amplifier for the Amplification of Very Low Electrophysiological Signals. Case of Electro Cardio Graphic Signals (ECG)
}

\author{
Guy Merlin Ngounou • Martin Kom
}

Published online: 21 January 2015

(C) Springer Science+Business Media New York 2015

Erratum to: J Med Syst (2014) 38:152

DOI 10.1007/s10916-014-0152-8

The original version of this article unfortunately contained errors. The details are provided below:

1st correction: (see article title)

\section{Instead of:}

Electrophisiological

Say:

Electrophysiological

2nd correction: (see page 2 of the article)

Instead of:

$\mathrm{F}=\frac{(\text { signal } / \text { noise })_{\text {at the input }}}{(\text { signal } / \text { noise })_{\text {at the input }}}$

Say:

$\mathrm{F}=\frac{(\text { signal } / \text { noise })_{\text {at the input }}}{(\text { signal } / \text { noise })_{\text {at the output }}}$

3rd correction: (see page 4 of the article)

The online version of the original article can be found at http://dx.doi.org/ 10.1007/s10916-014-0152-8.

G. M. Ngounou $(\bowtie) \cdot$ M. Kom

Automation and Control Laboratory (ACL), Department of

Coordination and Valorization of Research (CVR), National

Advanced School of Engineering, BP: 8390, Yaoundé, Cameroon

e-mail: ngounou_guy@yahoo.fr

\section{Instead of:}

$\Delta \mathrm{f}=\frac{\mathrm{f}_{\mathrm{T}}}{\mathrm{A}_{1}}$.

Say:

$\Delta \mathrm{f}_{1}=\frac{\mathrm{f}_{\mathrm{T}}}{\mathrm{A}_{1}}$.

4th correction: (see page 4 of the article)

Instead of:

$\mathrm{F}_{1}=\left(1+\frac{\mathrm{K}_{1}}{\mathrm{~A}_{1} \cdot \mathrm{K}_{\mathrm{e}}}\right) \sqrt{\frac{\mathrm{A}_{1} \cdot \Delta \mathrm{f}}{\mathrm{f}_{\mathrm{T}}}}$.

Say:

$\mathrm{F}_{1}=\left(1+\frac{\mathrm{K}_{1}}{\mathrm{~A}_{1} \cdot \mathrm{K}_{\mathrm{e}}}\right) \sqrt{\frac{\mathrm{f}_{\mathrm{T}}}{\mathrm{A}_{1} \cdot \Delta \mathrm{f}}}$

5th correction: (see page 4 of the article)

Instead of:

3- The gain bandwidth product $\left(\mathrm{A}_{1} \cdot \Delta \mathrm{f}\right)$ of the amplifier must be less than the cutoff frequency $\left(\mathrm{f}_{\mathrm{T}}\right)$ of the used operational amplifier.

Say:

3-The gain bandwidth noise product $\left(\mathrm{A}_{1} \cdot \Delta \mathrm{f}\right)$ must be higher than the cutoff frequency $\left(\mathrm{f}_{\mathrm{T}}\right)$ of the used operational amplifier. 